\title{
Revolusi Islam, Gerakan Islam dan Negara Islam: Studi Atas Pemikiran Politik Kalim Siddiqui
}

\author{
Mulyani \\ Mahasiswa Pasca Sarjana The Islamic College (IC)-Paramadina Jakarta dan anggota Lingkar Studi \\ Islam dan Kemasyarakatan (LSIK) Ciputat
}

\begin{abstract}
According to Siddiqui, Islamic movement is a tradional instru- ment for change. Islamic movement is not a political movement with a manifesto written by a committee. It also not an ideology conceptualized by philosophers, historians, activists, and thinkers from various faculties. The Islamic movement is purely the manifestation of God. So it will get His direct keep and maintenance. Starting from the movement led by the Prophet (PBUH), the corrective agents spread widely in Islamic history, like a labirint planted in political culture of Muslims.
\end{abstract}

Kata Kunci: gerakan Islam; kekuasaaan; perubahan; kekuatan korektif

\section{Pendahuluan}

Wacana gerakan Islam, revolusi Islam dan negara Islam kembali menarik untuk diperbincangkan mengingat telah terjadi perubahan politik di Timur Tengah yang sebagian besar dimotori oleh gerakan Islam. Pemahaman yang baik atas ketiga terma kunci di atas menjadi pintu masuk untuk memahami aspirasi dari gerakan revivalisme Islam yang selama ini hanya menjadi narasi kecil yang terabaikan dalam balutan penuh prasangka. Karya-karya para sarjana muslim dari kalangan revivalis sering dianggap non-akademis sehingga dinilai tidak ilmiah. Jika dikatakan bahwa banyak revivalis yang bersikap ekstrim dan hanya bermodalkan semangat tanpa didukung oleh tradisi ilmu, tentu saja penulis sepakat namun jika digeneralisir hal itu menjadi sikap ekstrim di sisi lain.

Kalim Siddiqui dapat dikategorikan sebagai revivalis muslim yang menarik untuk diperbincangkan mengingat ia merupakan salah seorang sarjana yang mencoba mengkonseptualisasikan teori revolusi Islam sekaligus pendukung revolusi Islam Iran. Terlebih lagi peta politik Timur Tengah sedang berpihak pada kekuatan-kekuatan yang sebelumnya dikenal sebagai kekuatan revi- valis dan makin menguatnya posisi Iran di tengah konstelasi politik dunia. Tulisan ini mencoba mendeskripsikan gagasan Kalim tentang ketiga isu tersebut dalam rangka memperluas dan memperdalam pengenalan akan fenomena gerakan revivalisme Islam di era modern.

\section{Revolusi Islam}

Bagi Kalim Siddiq, karakteristik politik Islam bukan hanya dipahami oleh generasi Islam awal, namun juga cukup dipahami oleh lawan politiknya yaitu rezim jahiliyyah Quraisy Makkah ketika itu. Bahkan, delegasi Quraisy yang dipimpin oleh Uthbah Ibn Rabi'ah sam-pai mendekati Rasulullah untuk menawarkan posisi kuasa. Namun Rasulullah menolak tawaran tersebut meskipun Rasul sangat membutuhkan kekuasaan sebagai instru- men untuk menerapkan Islam dengan efektif. Penolakan dilakukan karena kekuasaan yang diberikan tidak disertai dengan otoritas penuh untuk melakukan perubahan revolutif dan sistemik. Sedangkan risalah kenabian menurut Kalim memuat kekuatan transformatif yang mengubah secara radikal tatanan jahiliyyah. Kondisi yang Berbeda terjadi pasca hijrah, yang membuat Rasul menerima 
Konfrontasi: Jurnal Kultur, Ekonomi dan Perubahan Sosial, 3 (1) Januari 2016, 1-7

P-ISSN: 1410-881X (Print)

Mulyani, Revolusi Islam, Gerakan Islam dan Negara Islam: Studi Atas Pemikiran Politik Kalim Siddiqui

DOI: -

http://www.konfrontasi.net/index.php/konfrontasi2

kekuasaan dari masyarakat Madinah melalui serangkaian prosesi bai'at (sumpah setia). Proses pembai'atan merupakan pengakuan akan legitimasi kekuasaan Rasul dan sekaligus menandai berdirinya Negara Islam.

Rasulullah tidak menerima tawaran kekuasaan dari elit Quraisy bukan karena Rasul tidak memiliki visi kekuasaan akan tetapi Rasul ingin memimpin suatu tatanan yang bersifat indenpenden dimana Islam berdaulat secara penuh tanpa adanya negosiasi dan pragmatisme. Artinya, menurut Kalim, Rasul menginginkan terjadinya revolusi di tengah-tengah bangsa Arab menuju tatanan yang bersumber pada wahyu kenabian. Revolusi damai tersebut kemudian terwujud setelah Rasulullah hijrah ke Madinah.

Revolusi menurut Kalim akan mendapatkan momentumnya setelah ber- kembangnya suatu gagasan baru dalam jangka waktu yang cukup lama.

Gagasan baru pada awalnya diusung oleh sedikit orang yang kemudian disambut oleh sekelompok orang dan pada akhirnya diterima masyarakat luas.4 Gagasan baru dari sekelompok orang yang tercerahkan tersebut secara gradual melakukan tekanan untuk menuntut perubahan.5 Tekanan peru- bahan akan mendapatkan momentumnya di dalam sejarah setelah kekuatan perubahan tersebut mengalami konvergensi. Momentum dimana perubahan menyeluruh terjadi, inilah yang disebut oleh Kalim sebagai "Revolusi."

Kekuatan revolusi Islam sebagian mulai dibangun, sebagian tengah bergerak dan ada juga yang telah meraihnya (baca: Iran). Kekuatan revolusi Islam di era modern dipandang oleh Kalim akan bergerak mengalahkan dan merun- tuhkan negara bangsa pasca kolonial.

Kepemimpinan Islam tradisional yang Kalim sebut sebagai kepemimpinan muttaqi’ akan membangun negara Islam di atas puing-puing keruntuhan negara bangsa. Bagi Kalim, Muslim di belahan bumi manapun mesti menjadi bagian dari gerakan revolusi Islam. Revolusi-revolusi yang dilang- sungkan di seluruh negara Muslim harus diekspresikan secara luas dengan tujuan yang sama. Namun Kalim menyayangkan bahwa proses Revolusi Islam yang mencakup segenap kekuatan ummah sepertinya masih sedikit dipahami oleh kaum Muslimin. Padahal menurut Kalim, langkah revolusi merupakan jalan satu-satunya menuju negara Islam.

Kalim secara lantang mendukung revolusi Islam Iran, dimana ia menjadi eksponen utama yang secara aktif menjelaskan konsep revolusi tersebut di luar Iran.9 Revolusi yang dibayangkan oleh Kalim tidak bersifat serentak di seluruh bagian dunia Islam karena hal itu utopia. Menurut Kalim, Kaum Muslimin membutuhkan serial revolusi, dimana revolusi yang terjadi pada satu belahan wilayah tertentu akan berulang di belahan wilayah lainnya dari ummah. Pada tahap selanjutnya akan terjadi konvergensi dari bagian-bagian yang terpisah tersebut menuju terbentuknya negara Islam yang dalam terma yuridis teologis Islam dikenal dengan istilah khilafah atau imamah.

Kaum muslimin anak benua India, menurut Kalim, pada awalnya meyakini terben-tuknya negara Pakistan sebagai Revolusi Islam. Tetapi kenyataannya, pembentukan Pakistan tidak mengarah pada pendirian negara Islam. Sebaliknya, yang terjadi justeru membangun negara bangsa sekuler yang sebagian besar pemimpinnya korup dan secara politis tunduk terhadap Barat. Para pemimpin Pakistan awal, sebagaimana pemimpin di negara bangsa muslim lainnya dengan segera belajar menggunakan cara pandang yang Kalim sebut sebagai "Islam Amerika". Melalui cara pandang tersebut para rezim penguasa negeri-negeri muslim membungkus keterasingan mereka dari Islam dan mengokohkan paham negara bangsa.

Situasi dimana negeri-negeri muslim membangun tatanan kehidupannya di atas pondasi sekulerisme, menurut Kalim, keluar dari kondisi alaminya. Realitas tersebut mem-bawa pada 
Konfrontasi: Jurnal Kultur, Ekonomi dan Perubahan Sosial, 3 (1) Januari 2016, 1-7

P-ISSN: 1410-881X (Print)

Mulyani, Revolusi Islam, Gerakan Islam dan Negara Islam: Studi Atas Pemikiran Politik

Kalim Siddiqui

DOI: -

http://www.konfrontasi.net/index.php/konfrontasi2

keterasingan yang memunculkan bukan hanya krisis identitas, namun juga pada problemproblem yang lebih asasi dari itu (rusaknya tatanan kehidupan). Gerakan Islam mengambil peran sentral untuk bergerak mengembalikan tatanan ideal Islam. Gerakan Islam yang menjadi wadah bagi konvergensi kekuatan transformatif berupaya mencari memon-tumnya untuk melahirkan revolusi Islam. Mengingat pentingnya peran gerakan Islam untuk melahirkan revolusi Islam dan negara Islam maka berikut akan dijelaskan apa yang Kalim maksud dengan gerakan Islam.

\section{Gerakan Islam}

Di masa Rasulullah, kaum Muslimin yang telah menerima Islam segera bergabung ke dalam gerakan Islam yang dipimpin oleh Rasul sendiri. Kalim memahami bahwa Al-Qur'an telah menyeru partisipasi dan komitmen total setiap Muslim untuk mengerahkan seluruh potensi yang mereka miliki untuk melakukan perjuangan mendirikan negara Islam. Metode perubahan yang diaplikasikan oleh Nabi hanya berdasarkan pada wahyu kenabian dan dimotori oleh gerakan Islam.

Gerakan Islam merupakan intrumen tradisional bagi perubahan. Gerakan Islam bagi Kalim bukanlah gerakan politik dengan sebuah manifesto yang ditulis oleh sebuah komite. Gerakan Islam juga bukan sebuah ideologi yang dikonseptualisasikan oleh filosof, sejarawan, aktivis dan pemikir dari ber- bagai aliran. Gerakan Islam secara murni merupakan manifestasi kehendak Tuhan. Sehingga juga mendapat perlindungan langsung dari Allah.14 Gerak- an Islam pertama dan paling sempurna tidak lain adalah gerakan yang dipimpin oleh Rasulullah Muhammad SAW di semenanjung Arabia. Selan- jutnya, agen korektif tersebut tersebar di dalam bentangan sejarah Islam, layaknya labirin kekuatan korektif tertanam di dalam budaya politik kaum muslimin, tegas Kalim.

Gerakan Islam dalam dinamikanya sangat mungkin mengalami kemun- duran, frustasi atau bahkan kekalahan. Hal ini dapat diilustrasikan dengan amat jelas dari beberapa peristiwa masyhur yang terjadi di dalam kehidupan Rasulullah secara individu dan pada gerakan Islam masa itu, baik ketika berada di Mekah maupun di Madinah. Periode Mekah menampilkan upaya Quraisy untuk menghambat perubahan dan menggangu keberadaan embrio gerakan Islam. Nabi memerintahkan kaum Muslimin untuk hijrah ke Ha-basyah hingga kondisi di Mekah kembali aman bagi gerakan Islam. Sedangkan di Madinah, kemenangan pertama diraih oleh kaum Muslimin dalam perang Badar, meskipun diikuti kekalahan dalam perang Uhud. Beberapa tahun kemudian terjadi perjanjian Hudaibiyyah yang merupakan kemenangan gerakan Islam. Semua kemunduran, hijrah, kemenangan dan kekalahan dialami oleh gerakan Islam pada masa Rasulullah. Namun menurut Kalim, gerakan Islam pada akhirnya menjadi pemenang atas kekuatan-kekuatan jahiliyyah dan segera membangun Negara Islam.

Persoalan yang dihadapi gerakan Islam saat ini juga terdapat di masa Rasulullah. Tentu dengan skala yang berbeda, meski secara kualitatif prob- lemnya tetap sama. Kalim mencontohkan, tribalisme pada masa jahiliyyah telah mewujud dalam bentuk nasionalisme di masa kini. Eksploitasi buruh oleh kapitalisme adalah kemasan baru dari tradisi perbudakan jahiliyyah. Oleh karena itu metode perjuang Rasulullah untuk membangun tatanan ideal Islam akan tetap relevan dan bersifat meta-historis. Terakhir Kalim menyimpulkan bahwa segala bentuk kekuatan oposisi untuk menghadapi gerakan Islam dicap oleh Kalim dengan neo-jahiliyyah. 
Konfrontasi: Jurnal Kultur, Ekonomi dan Perubahan Sosial, 3 (1) Januari 2016, 1-7

P-ISSN: 1410-881X (Print)

Mulyani, Revolusi Islam, Gerakan Islam dan Negara Islam: Studi Atas Pemikiran Politik

Kalim Siddiqui

DOI: -

http://www.konfrontasi.net/index.php/konfrontasi2

Sebelum kedatangan nabi akhir zaman Rasulullah, proses korektif dilakukan oleh banyak nabi yang diturunkan secara suksesif. Saat ini, peran perbaikan (correction) dan penyatuan (convergence) ummah dilakukan oleh agen- agen non-prophetic yang terdiri dari individuindividu, gerakan Islam dan negara Islam (Kalim menunjuk Iran pasca revolusi 1979 sebagai Negara Islam). Bagi Kalim, Agen-agen korektif mesti memiliki powers untuk mengubah seluruh bagian dari tubuh ummah menuju penyatuan (convergence) ke arah tegaknya Islam. Artinya, agen-agen korektif manapun dalam tubuh ummah harus memiliki visi politik yang jelas dan meraih kekuasaan sebagai instrumen efektif dalam mewujudkan ideal Islam.18

Telah muncul di dunia Islam sejumlah individu dan berbagai gerakan yang menjadi agen korektif akan tetapi mereka gagal. Mereka di antaranya; Hasan al-Banna (pendiri Ikhwan alMuslimin) dan Maulana Abul 'Ala al-Maududi (pendiri Jama'ati al-Islami).19 Mereka dinilai gagal oleh Kalim karena tidak mampu membangun negara Islam. Perjuangan membangun negara Islam menjadi persoalan utama demi mengakhiri penyimpangan (deviation) yang terjadi di tengah-tengah ummah. Kegagalan kedua gerakan di atas menun- jukkan bahwa agen korektif yang efektif hanya dapat dilakukan oleh negara Islam, tegas Kalim.

Sejarah politik kaum Muslimin dipenuhi dengan beragam kesalahan dalam penerapan atau bahkan penyimpangan dalam rentang waktu yang cukup lama. Sejarah Islam menurut Kalim hanya mengalami masa ideal kurang lebih dua atau tiga dekade setelah era kenabian. Masa ideal itulah yang menjadi guidance bagi kaum Muslimin untuk menata masa depannya.

Bagi Muslim sunni tidak ada kondisi vakum dalam kepemimpinan, yang ada secara gradual mengalami kemunduran. Mazhab sunni mengakui keutama- an khulafa' al-Rasyidun. Perubahan kualitas kepemimpinan sebagai bentuk penyimpangan awal terjadi ketika Mu'awiyah bin Abi Sufyan menjadi pemimpin atau lebih tepatnya menjadi raja. Kalim mengkritik sikap ulama sunni yang tidak melakukan konfrontasi terbuka terhadap rezim kerajaan menyimpang (malukiyyah) tersebut. Ketika rezim malukiyyah mengganti kekhilafah-an menjadi kerajaan, hal itu sangat disadari oleh para ulama sunni, namun mereka memilih untuk tidak melakukan upaya pembe- rontakan. Sebaliknya, mereka menerima dengan mudah dan hampir mem- bai'at secara otomatis pewarisan tahta malukiyyah, meskipun penguasa ter- sebut lemah secara politik dan menyimpang secara moral.

Menurut Kalim, penyimpangan yang terjadi di dunia sunni didasarkan pada adanya justifikasi yuridis terhadap kekuasaan malukiyyah.22 Kalim ingin menunjuk adanya konsep dimana tidak dibenarkannya melakukan pembe- rontakan terhadap raja dikarenakan akan menimbulkan kerusakan yang lebih parah.23 Konsep ini memberi peluang kepada banyak aktivis sunni untuk dengan mudah menjadi "ulama penguasa". Mereka menikmati patro- nase politik penguasa sehingga membelenggu mereka. "Kita mesti berhenti untuk menggunakan pandangan seperti ini," tegas Kalim.

Dalam jangka waktu lama para penguasa Muslim memanfaatkan kekuatan sedapat mungkin untuk memimpin imperium yang luas. Perluasan impe- rium, membangun kotakota, tempat-tempat pembelajaran dan dominasi politik, telah melenakan kaum muslimin. Kasalahan dan penyimpangan dari Islam dengan pemerintahan berbentuk malukiyyah ditutupi oleh banyaknya ekspansi dan kesuksesan kekuatan politik Muslim. Kemunduran tidak terasa nyata selama kaum Muslim terus melakukan penaklukan (futuhat). 25

Di era kontenporer, agen-agen korektif yang tersebar dalam kapasitas individu atau kolektif partai dilihat oleh Kalim masih sangat lemah. Proses korektif di dunia sunni baru dimulai dengan susah payah dan tertatih-tatih. Pemikiran politik yang konprehensif dan 
Konfrontasi: Jurnal Kultur, Ekonomi dan Perubahan Sosial, 3 (1) Januari 2016, 1-7

P-ISSN: 1410-881X (Print)

Mulyani, Revolusi Islam, Gerakan Islam dan Negara Islam: Studi Atas Pemikiran Politik

Kalim Siddiqui

DOI: -

http://www.konfrontasi.net/index.php/konfrontasi2

kokoh dalam tradisi Sunni masih belum ditemukan. Agak sedikit berbeda halnya dengan dunia Syi'ah yang telah meraih tangga revolusi Islam (Iran). Gerakan yang tumbuh di dunia Islam seperti "Partai-Partai Islam", Nasionalisme Arab dan Khilafat Move- ment dilihat oleh Kalim telah dibelokkan dari metode yang benar oleh patro- nase penguasa.26 Ditambah lagi ulama dan intelektual yang sebelumnya diharapkan melakukan perbaikan namun justru bernegosiasi dengan kondisi pragmatis yang ada. Sebagai imbalannya, mereka mendapatakan patronase politik dari kekuasaan menyimpang. Patronase politik dinikmati dalam suasana ketundukan yang hina selaman 1400 tahun.27 Namun demikian Kalim tetap optimis bahwa kekuatan korektif di dalam tubuh ummah akan senantiasa lahir.

Jika gerakan Islam sebagai kekuatan korektif mengikuti metode perjuangan yang dilakukan oleh nabi maka akan menghasilkan hasil yang spektakuler. Namun menurut Kalim, hasil yang spektakuler tersebut mesti ditopang oleh jerih payah dan kesungguhan perjuangan dalam waktu yang lama.28 Untuk membuat batasan yang jelas terhadap apa yang dimaksud sebagai gerakan Islam, penulis mengajukan definisi Kalim tentang gerakan Islam. Kalim menulis:

"The Islamic movement may be defined as the struggle of the Muslim to establish, maintain, develop, defend, extend or reestablish the Islamic state as an instrument to enjoin good and forbide evile for the walfare and happiness of all mankind in this world and in the hereafter."

Kalim berpandangan bahwa inti dari perjalanan hidup Rasulullah adalah perjuangan gerakan Islam dalam mendirikan negara Islam. Urgensi negara Islam membuat Kalim berpandangan bahwa ikut serta dalam perjuangan gerakan Islam merupakan kewajiban setiap Muslim. Di masa Rasullullah, seluruh kaum Muslimin terlibat secara total dalam perjuangan bersama Rasulullah. Kalim menyatakan:

"The point that has to be understood clearly is that the Islamic State and Islamic movement are part of a whole; Islam is incomplete without the Islamic State. In the sense that the stuggle of the Islamic movement to establish the Islamic State is at the very heart of the sunnah of the prophet."

Al-Qur'an dan sunnah memang merupakan sumber nilai yang tetap, akan tetapi gerakan Islam dan negara Islam merupakan variabel dinamis, dimana corak luarannya berkembang mengikuti perkembangan zaman. Menariknya, semua bagian konsep Islam termasuk persoalan gerakan Islam dan Negara Islam, merupakan perpaduan antara nilai-nilai yang tetap dengan faktor-faktor yang bersifat dinamis. Artinya, para sarjana Muslim mesti mem- bangun dan menyusun berbagai gagasan, teori dan kebijakan baru dan relevan untuk realita kekinian. Seluruh teori dan kebijakan tersebut harus sesuai dengan framework Islam yang digali dari perjalanan hidup Ra- sullullah (sirah dan sunnah).

Setelah revolusi Iran, Kalim menyadari efek yang muncul berupa energi penggerak yang luar biasa terhadap gerakan Islam global. Di bawah kepe- mimpinan republik Islam Iran, ia berharap energi besar ini memberi dorongan yang cukup untuk melahirkan negara Islam global. Energi besar ini mendapat sedikit sandungan dengan adanya sebagian kalangan di Iran yang menginginkan revolusi terbatas pada Iranian saja. Gerakan Islam, tegas Kalim, harus mencapai tingkat kohesi kaum Muslimin sehingga dapat me- mobilisasi mereka demi meraih tujuan tertingginya, mendirikan negara Islam global. 
Konfrontasi: Jurnal Kultur, Ekonomi dan Perubahan Sosial, 3 (1) Januari 2016, 1-7

P-ISSN: 1410-881X (Print)

Mulyani, Revolusi Islam, Gerakan Islam dan Negara Islam: Studi Atas Pemikiran Politik

Kalim Siddiqui

DOI: -

http://www.konfrontasi.net/index.php/konfrontasi2

\section{Negara Islam}

Sepuluh tahun terakhir dari masa kenabian telah mentransformasi jazirah Arab jahiliyyah menjadi negara Islam. Transformasinya bersifat menyeluruh dengan berdirinya suatu tatanan baru yang menjadi medium alami bagi kehidupan Islam. Corak kehidupan di bawah tatanan inilah yang menjadi tujuan dari Islam. Islam mengganti semua corak ikatan-ikatan sosial lama menuju satu bentuk ikatan-ikatan sosial baru.33 Untuk memperjelas apa yang dimaksud oleh Kalim dengan Negara Islam, berikut definisinya:

"The Islamic state is a state in which the leadership, the government and the people have a single difined purpose. This can only happen if the leadership is clearly and demonstrably muttaqi. And if the bay'a or obedience given by the populace is also equally clearly and demonstrably base on taqwa. Taqwa or piety, holds and binds the political system of Islam together. The system then dispenses 'adl (justice) to all. It is the taqwa of all its component parts and their combine output, "Adl that legitimise the Islamic state."

Setelah hijrah ke Madinah, menurut Kalim, Islam memasuki transisi menuju pembentukan negara (statehood). Setelah itu, penyebaran Islam ke seluruh jazirah Arab mengalami perkembangan yang cepat dan luas. Keberadaan negara memiliki implikasi besar bagi dakwah Islam. Kalim menyatakan “...the chief instrument of da'wah is the Islamic State; da'wah without the Islamic State is like an invitation without an address.35 Aktifitas da'wah di era pasca colonial menyerap banyak energi kaum Muslimin namun hanya melanggengkan status quo. Dakwah dikendalikan oleh patronase kekuasaan rezim negara bangsa Muslim yang mengalihkan dakwah tersebut dari tujuan tertingginya mendirikan negara Islam.

Setiap kaum Muslimin harus terlibat dalam perjuangan mendirikan negara Islam.36 Keterlibatan ini menurut Kalim merupakan kewajiban atas mereka dari Allah. Kaum Muslimin mesti mengambil peran dalam perjuangan men- dirikannya baik dalam level intelektual maupun aktivitas politik. Pengem- bangan intelektual dan dukungan politik menjadi satu paket perjuangan dalam wadah gerakan Islam.

Kekuatan revolusi Islam yang dihasilkan oleh kepemimpinan muttaqi’ akan mengalahkan dan menghancurkan negara bangsa pasca kolonial, yang berlanjut dengan pendirian negara Islam. Kaum Muslimin di seluruh dunia telah mengambil bagian dalam perjuangan Islam. Akan tetapi perjuangan total yang bersifat mencakup masih sedikit dipahami. Artinya, tidak seluruh perjuangan kaum Muslimin memiliki visi revolusi Islam dan negara Islam.37

Kalim berpandangan bahwa pada dasarnya seluruh kaum Muslimin meng- inginkan terbentuknya negara Islam. Negara Islam atau sistem khilafah me- rupakan organisasi politik warisan Rasulullah yang merupakan medium untuk mengaplikasikan seluruh nilai-nilai Islam. Kalim menyatakan:

"All Muslim wish to live in the Islamic state because the Islamic state is the natural habitat of the Muslim. This is because the Islamic state or the khilafah, is the final shape given to the ummah by great exemplar, the prophet of Islam, upon whom be peace." 38

Negara Islam dan gerakan Islam tidak bisa dipisahkan dan pemahaman tentang keduanya sangat jelas. Di sini Kalim ingin menyatakan bahwa Islam tidak lengkap tanpa negara Islam. Oleh karena itu perjuangan gerakan Islam berorientasi untuk mendirikan negara Islam. Negara Islam cukup sentral bagi Kalim, yaitu merupakan jantung dari sunnah Rasulullah.

Negara Islam mungkin saja mengalami kekalahan dan kehancuran oleh serangan musuh. Negara Islam juga mungkin untuk mengalami penyim- pangan yang jauh dari nilai-nilai Islam sehingga tidak lagi bisa diakui sebagai negara Islam. Namun “...it (islamic state) is impossible 
Konfrontasi: Jurnal Kultur, Ekonomi dan Perubahan Sosial, 3 (1) Januari 2016, 1-7

P-ISSN: 1410-881X (Print)

Mulyani, Revolusi Islam, Gerakan Islam dan Negara Islam: Studi Atas Pemikiran Politik

Kalim Siddiqui

DOI: -

http://www.konfrontasi.net/index.php/konfrontasi2

to lose the Islamic movement altogether, because no matter how great the defeat or diviation, there will always be Muslims who will struggle for the resto- ration of the Islamic state."39 Di sinilah fungsi gerakan Islam untuk menjaga negara Islam dari kekalahan dan mengatasi kekuatan penyimpangan internal.

Islam sesungguhnya merupakan risalah yang mencakup metodologi. Kalim berdalil bahwa inilah yang menyebabkan adanya banyak penegasan dalam Islam, dimana sunnah dan sirah menjadi metode aplikatif dalam menja- lankan Islam. Dan ini juga yang membuat prosedur penerapan Islam dan proses berjalannya sejarah Islam membutuhkan pendirian negara Islam sebagai bagian yang tidak dapat dipisahkan dari Islam. Kalim kemudian menyimpulkan: "Islam, therefore, is incomplete without the Islamic State."

\section{Kesimpulan}

Gerakan Islam menjadi motor penggerak untuk meraih revolusi yang mendapatkan momentumnya setelah terjadi konvergensi dari berbagai elemen kekuatan perubahan. Revolusi Islam akan mengarah pada pem- bentukan Negara Islam yang akan menjadi medium alami bagi terwujudnya tatanan ideal Islam.

\section{Bibliografi}

Kalim Siddiqui, Stages of Islamic Revolution and Processes of Error, Deviation, Correction and Divergence in Muslim Political Thought (Kanada; United Kingdom, The Crescent International and Petaling Jaya, the Other Press, first published 1996, fourth Published 1999)

The Institute of Contemporary Islamic Thought (ICIT), "Obituary: Dr Kalim Siddiqui, 1931 1996," http://wwwv.islamicthought.org/ks-home.html, diakses pada Jum'at 6 Maret 2009.

Kalim Siddiqui, Issues in the Islamic Movement (London, the Open Press Limited, 982),

Kalim, Seruan- seruan Islam 